\title{
The basal roughness of Pine Island Glacier, West Antarctica
}

\author{
D.M. RIPPIN, ${ }^{1}$ D.G. VAUGHAN, ${ }^{2}$ H.F.J. CORR ${ }^{2}$ \\ ${ }^{1}$ Environment Department, University of York, Heslington, York YO10 5DD, UK \\ E-mail: david.rippin@york.ac.uk \\ ${ }^{2}$ British Antarctic Survey, Natural Environment Research Council, Madingley Road, Cambridge CB3 OET, UK
}

\begin{abstract}
We assess basal roughness beneath Pine Island Glacier (PIG), West Antarctica, based on a recent airborne radio-echo sounding dataset. We identify a clear relationship between faster ice flow and decreased basal roughness in significant parts of PIG. The central portion and two of its tributaries are particularly smooth, but the majority of the tributaries feeding the main trunk are rougher. We interpret the presence of a smooth bed as being a consequence of the deposition of marine sediments following disappearance of the West Antarctic ice sheet in the Pliocene or Pleistocene, and, conversely, a lack of marine sedimentation where the bed is rough. Importantly, we also identify a patchy distribution of marine sediments, and thus a bed over which the controls on flow vary. While there is a notable correspondence between ice velocity and bed roughness, we do not assume a direct causal relationship, but find that an indirect one is likely. Where low basal roughness results in low basal resistance to flow, a lower driving stress is required to produce the flux required to achieve mass balance. This, in turn, means that the surface in that area will be lower than surrounding areas with a rougher bed, and this will tend to draw flow into the area with low bed roughness. Since our studies shows that bed roughness beneath the tributaries of the trunk varies substantially, there is a strong likelihood that these tributaries will differ in the rate at which they transmit current velocity changes on the main trunk into the interior of the glacier basin.
\end{abstract}

\section{INTRODUCTION}

Basal roughness is the vertical variation in the ice/subglacial-bed interface with distance in the horizontal plane (Siegert and others, 2004, 2005; Taylor and others, 2004; Rippin and others, 2006a; Bingham and Siegert, 2007, 2009; Bingham and others, 2007). In attempting to understand the flow dynamics of ice sheets, and predict future changes, it is critical to understand how roughness variations impact upon ice dynamics. In this paper, we assess the roughness beneath Pine Island Glacier (PIG), which drains $\sim 175000 \mathrm{~km}^{2}$ of the West Antarctic ice sheet (WAIS; Vaughan and others, 2001). It consists of a series of tributaries and a main trunk (Fig. 1; Stenoien and Bentley, 2000). Recent thinning and retreat (Rignot, 1998; Shepherd and others, 2004) suggests it may be particularly vulnerable to the rate at which the ocean melts ice close to the grounding line. Close to the grounding line, PIG is particularly fast-flowing $\left(>2.5 \mathrm{~km} \mathrm{a}^{-1}\right)$ and shares many features (such as occupying a deep trough) with rapidly changing glaciers in Greenland, such as Jakobshavn Isbræ (Stenoien and Bentley, 2000; Truffer and Echelmeyer, 2003; Vaughan and others, 2006). As a consequence of recent periods of acceleration, PIG is currently no longer in balance, but it is uncertain whether this imbalance indicates the onset of a deglaciation of the basin, or is simply a short-term (multidecadal to century) fluctuation (Vaughan and others, 2006). We have only a limited understanding of the mechanisms behind recent changes, in part because of a lack of data and knowledge of conditions at the bed.

We are interested in the roughness of the PIG bed because, in general, the resistance that roughness exerts upon ice flow is regionally the most significant stress opposing the glacier driving stress. Since a glacier, or ice sheet, will tend to thicken until the driving stress produces ice flow to maintain the 'balance flux', a bed that has a low roughness, and which provides little restraint on ice flow, will achieve balance flux with relatively less thickness and less surface slope. The magnitude of the basal stress exerted by the bed is controlled by roughness and subglacial water pressure (Iken, 1981; Bindschadler, 1983; Lliboutry, 1987; Jansson, 1995; Willis, 1995; Harper and others, 2007). While many studies have sought to relate subglacial water pressures to basal motion (e.g. Iken, 1981; Bindschadler, 1983; Jansson, 1995; Harper and others, 2007), only a few concern the relationship between bed roughness and basal motion; this may in part be due to the difficulty of measuring subglacial roughness (Bennett, 2003; Taylor and others, 2004). Bed echoes from radio-echo sounding (RES) across the Antarctic ice sheet (and other ice bodies) provide data from which bed roughness can be assessed. To date, however, only a few researchers have tackled this issue, using a range of methods to extract roughness from bed echoes across a range of scales (e.g. Hubbard and others, 2000; Taylor and others, 2004; Siegert and others, 2005; Rippin and others, 2006a; Bingham and Siegert, 2007, 2009; Bingham and others, 2007). Our objective is to assess basal roughness beneath the drainage basin of PIG, and the possible future behaviour of the glacier in response to future changes.

\section{METHODOLOGY}

We used unmigrated data acquired from airborne radioecho sounding (RES) profiles, collected as part of an aerogeophysical survey of the Amundsen Sea sector of West Antarctica, in the austral summer of 2004/05 (Vaughan and others, 2006). Due to resolution considerations, discussed below, migration was not necessary. Thirty airborne RES sorties were flown over the PIG basin from a field camp and fuel depot located at $77^{\circ} 34^{\prime} \mathrm{S}, 95^{\circ} 56^{\prime} \mathrm{W}$ (Fig. 1). The RES system was fitted in a Twin Otter aircraft, also equipped with 


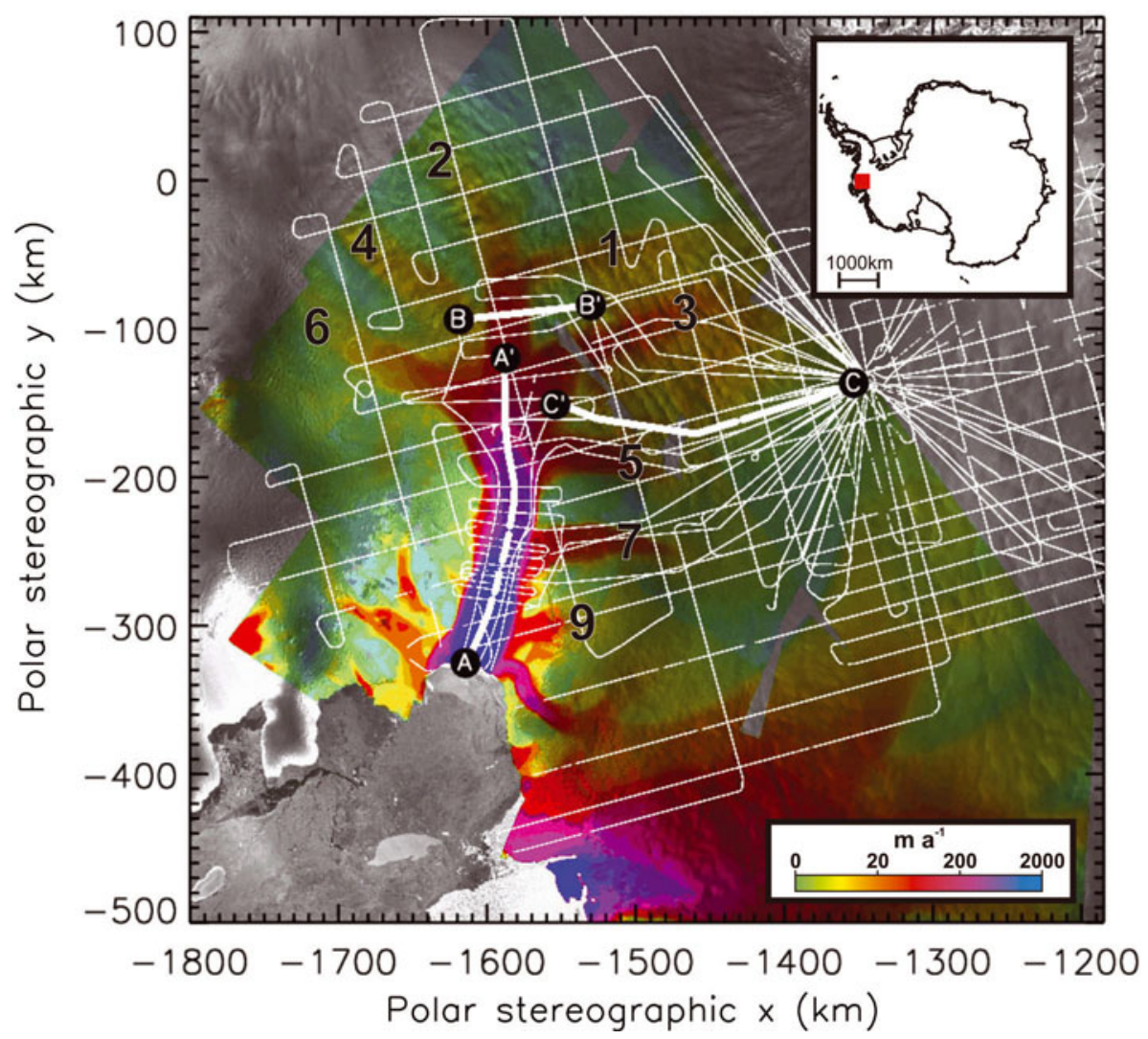

Fig. 1. RES flight tracks (thin white lines) over the Pine Island region. Grey-shaded background shows part of the RADARSAT Antarctic Mapping Project (RAMP) mosaic of Antarctica (K. Jezek and RAMP Product Team, http://nsidc.org/data/nsidc-0103.html), overlain with interferometric synthetic aperture radar (InSAR) velocities (colour shading; Rignot and others, 2004). The trunk of PIG is clearly visible as a high-velocity region (blue/purple), with a number of tributaries of lesser velocity (red/yellow). Numbering of the tributaries is according to the scheme originally presented by Stenoien and Bentley (2000; cf. Vaughan and others, 2006). Thick white lines represent sample sections of a single flight line: $\mathrm{A}-\mathrm{A}^{\prime}$ represents a section along the trunk of PIG and part of Tributary 2; B-B' is a section directly cutting across Tributary 2, while section $\mathrm{C}^{-} \mathrm{C}^{\prime}$ is a section from a slow-flow region beyond the tributaries (see Fig. 2). Inset shows the location of the study area in Antarctica, marked with a red square.

dual-frequency carrier-phase GPS for navigation and a radar altimeter for determining surface elevation (Vaughan and others, 2006). The RES system had a transmit power of $4 \mathrm{~kW}$, a centre frequency of $150 \mathrm{MHz}$, and applied a chirp pulse compression to a coherent stack of 25 sequential traces, giving one trace every $3.2 \mathrm{~ms}$. Every ten traces were incoherently stacked. The resultant data, decimated to give an effective along-track sampling rate of $3 \mathrm{~Hz}$, were then converted to seismic format (SEG-Y). We picked the position of the bed reflectors using the seismic processing package ProMAX. We used a radar wave velocity of $0.168 \mathrm{~m} \mathrm{~ns}^{-1}$ to calculate ice thickness from two-way travel time, and added $10 \mathrm{~m}$ to account for increased speed in firn. More detailed information on the system employed and an overview of the data acquired were reported by Vaughan and others (2006).

Comparisons of ice thickness recorded at flight-line crossover points indicated a root-mean-square (RMS) error of $\sim 23 \mathrm{~m}$ (Vaughan and others, 2006). The RMS crossovers in measurements of ice-surface elevation were considerably lower ( 0.82 m; Vaughan and others, 2006, 2007), so we take the uncertainty in bed-elevation measurement to be roughly equivalent to that in the ice thickness. The alongtrack spacing between samples varied as a consequence of variations in the aircraft speed. However, sample spacing was of the order of 15-30 m in most cases.

To assess basal roughness, we applied a forward fast Fourier transform (FFT) to the bed elevations derived from the radar sections (Taylor and others, 2004; Bingham and others, 2007). The approach transforms bed elevation data in a moving window, into the frequency domain using a FFT. Roughness is then defined as the integral of the resultant power spectra in any one moving window (cf. Taylor and others, 2004). There were several steps to the FFT analysis, as follows:

1. We interpolated where there were less than ten consecutive missing points (a gap of less than $\sim 340 \mathrm{~m}$ ). Occasional missing data points are not uncommon in RES data because of system errors or an inability to identify the bed reflection. Thus interpolation across small data gaps maintains continuity in the FFT analysis. Where a gap of ten or more points occurred, the line was classified as 'broken' and no interpolation was performed. Subsequent FFT analysis was thus restarted down-profile where sufficient sequential data became available.

2. Each section of unbroken line was then resampled at a regular $34 \mathrm{~m}$ step size (the approximate mean sample spacing of all flights) to account for the variable sample spacing, and to ensure that smoothing (step 3) occurred over a consistent distance.

3. We removed large-scale topographic variations from the raw data by subtracting a running-mean topography over a moving window of 100 sample points. This resampling 
created an implicit smoothing over a distance of $3400 \mathrm{~m}$ (i.e. $100 \times 34 \mathrm{~m}$ samples). This approach means we observed roughness over distances that might be classed as local rather than regional, although in reality we were not able to assess roughness over the smallest scales.

4. We performed a FFT over $2^{N}$ samples, where $N=5$. This equates to an FFT window of 32 data points (equal to $1088 \mathrm{~m}$ ). Several authors (Brigham, 1988; Taylor and others 2004; Bingham and others 2007) indicate that this is the minimum value of $N$ that should be used. Longer windows are not desirable because they tend to reduce the significance of the shorter-wavelength roughness information, which is of primary interest. As mentioned above, this still only means roughness over scales of the order of $1 \mathrm{~km}$. The measure of bed roughness was then defined as the integral of the resultant FFT of power spectra over each window and was plotted at the centre point of that window.

Bed roughness is undoubtedly present at all spatial wavelengths and a range of amplitudes. Our analysis is sensitive to a specific domain of wavelength-amplitude roughness scales. Consideration of the acquisition characteristics of the system and details of the analysis allows us to estimate the limits of this domain. Firstly, our radar data are fundamentally sensitive only to the along-track roughness; cross-track roughness is largely invisible to us. Secondly, irrespective of spatial wavelength there is a lower limit on the amplitude of the roughness that we can properly measure. This arises from the resolution of the radar system and is unlikely to be better than the mismatches in bed elevation (RMS values) at crossovers, which is $\sim 23 \mathrm{~m}$. Noise may exist below this level, but it should have a constant amplitude across the entire survey. Thirdly, the maximum and minimum spatial wavelengths of roughness that we can see are limited by the along-track sampling interval (15-30 m originally, resampled at $34 \mathrm{~m}$ ) and the length of the filtering window $(\sim 1088 \mathrm{~m})$. Finally, the maximum amplitude of roughness that can be seen at a particular spatial wavelength in unmigrated data is limited by the degree to which overlapping hyperbolae allow a bottom echo to be tracked. If the ice bottom is picked as the first basal return (as we have done), then two overlapping hyperbolae produced by point reflectors at a horizontal distance, $\lambda$, apart and depth, $d$, below the ice surface, will obscure any reflector between them that is greater than a depth, $\beta$, below them. A simple geometric analysis shows that

$$
\beta=\frac{\lambda^{2}}{8}\left(\frac{h c_{\mathrm{i}}}{c_{0}}+d\right)^{-1},
$$

where $h$ is the height of the radar above the ice surface, and $c_{\mathrm{i}}$ and $c_{0}$ are the speed of radar waves in ice and air respectively.

Altogether, the above conditions allow us to fully describe the spatial wavelengths and amplitudes of roughness to which the method we used is sensitive (Fig. 2). This set of scales may not include all those that are likely to affect ice flow, but it does include significant components that might influence ice flow and be altered by the ice flow.

Following the steps outlined above, we analysed roughness along track, and then finally interpolated within the region of study. We gridded the logarithm of our measure of roughness using an inverse-distance weighting procedure, limited to searching in a $20 \mathrm{~km}$ radius. Resultant

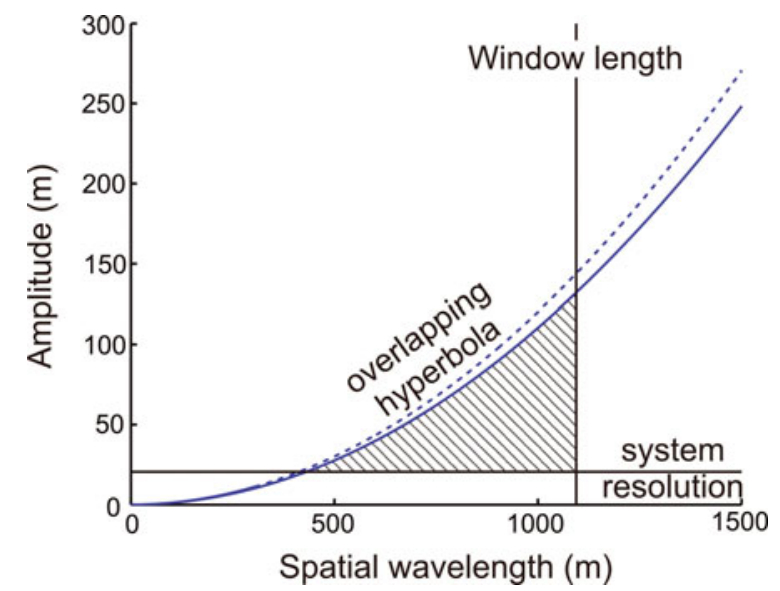

Fig. 2. Indication of the ability of our radar system and processing scheme to discriminate particular spatial wavelengths and amplitudes of basal roughness. The hatched area shows the area of sensitivity, limited by the length of the averaging window, the system resolution, and the effective smoothing implied by overlapping hyperbolae. There is a marginal difference between the aircraft flying at $150 \mathrm{~m}$ above the ice surface (dashed curve) and $500 \mathrm{~m}$ above the ice surface (solid curve).

roughness was then compared with modern-day surface velocities and topography.

\section{RESULTS}

Figure 3 shows bed elevation and bed roughness along three distinct portions of a single flight (known as B14). Figure 3a is over regions of fast flow along the trunk of PIG and part of Tributary 2; Figure $3 \mathrm{~b}$ is over a region cutting across Tributary 2 ; and Figure $3 c$ is over a region of slow flow outside the tributaries (cf. Fig. 1; naming convention is after Stenoien and Bentley, 2000). This flight was chosen because it was recorded along the main trunk and part of a tributary, across the same tributary, and over an extra-tributary area. In each case, resampled bed topography is shown in black, while the along-track bed roughness, calculated as the log of the integral of the power spectra over a 32-point moving window, is overlain in red. Gaps in the data (where FFT analysis could not be carried out) are clearly visible, particularly in Figure 3a and $c$. The mean roughness of each section is summarized in Table 1. Section B-B', which crosses Tributary 2, can be subdivided into two sections (at $\sim 726 \mathrm{~km}$ along track), one within the tributary and one outside the tributary. Roughness in these two sections is summarized in Table 2.

The summary data in Tables 1 and 2 indicate that the bed is roughest where velocities are lowest (section $C-C^{\prime}$ and the extra-tributary part of section $B-B^{\prime}$ ). The smoothest bed occurs where ice flow is fastest, i.e. in section $A-A^{\prime}$, directly along the main trunk of PIG and Tributary 2, and also the part of section B-B' found within Tributary 2. Roughness is indicated both by the lower calculated roughness values, and also as generally indicated by reduced roughness variability (indicated by the standard deviation). Conversely, rougher beds have higher roughness values and generally greater variability.

Figure 4a shows bed topography (after Vaughan and others, 2006), while Figure $4 \mathrm{~b}$ shows roughness contoured and shaded over the whole of PIG. The quantity shown here is the log of our roughness measure, gridded using an 

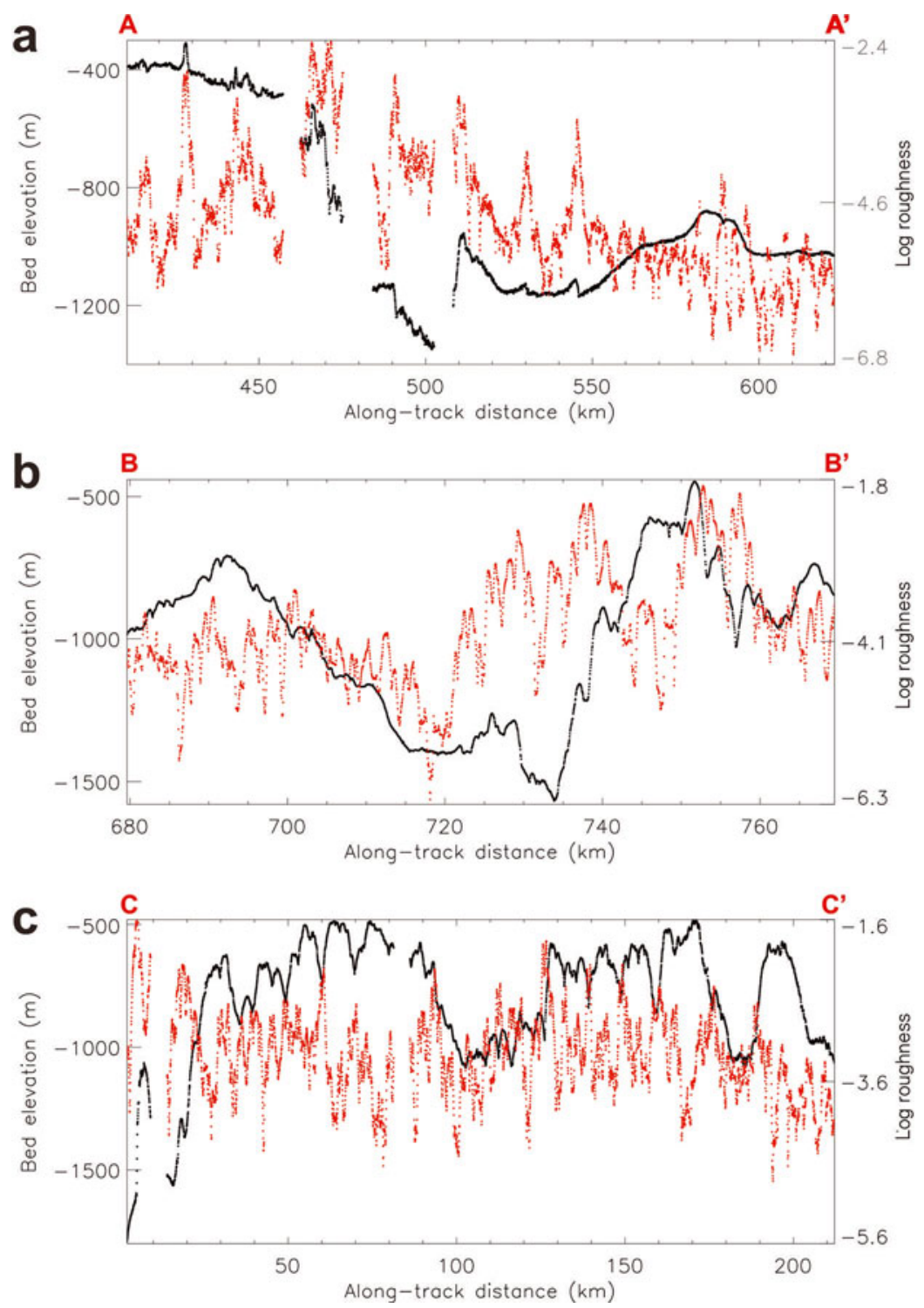

Fig. 3. (a) Raw bed elevation (black) and roughness (red) properties along flight-line section $A-A^{\prime}$. The roughness is the integral of the power spectra at the centre point of a 32-point-wide moving window. (b) and (c) are identical to (a), but for sections B-B' and C- $\mathrm{C}^{\prime}$ respectively.

inverse-distance weighting procedure that was limited to searching in a $20 \mathrm{~km}$ radius. Figure $4 \mathrm{c}$ shows interferometric synthetic aperture radar (InSAR) velocities (after Rignot and others, 2004). Roughness is derived from 33 separate

Table 1. Summary of roughness statistics along three portions of a single flight-line (B14) which crosses regions of differing flow characteristics (cf. Fig. 3). Roughness is expressed, firstly, as the derived value from the FFT analysis and, secondly, as the log of this, in line with graphic representations of roughness in Figures 3-5. Roughness units are dimensionless. SD is standard deviation

Section Characteristics Mean Mean log SD SD log
roughness roughness roughness roughness

\begin{tabular}{lccccc}
\hline A-A' & $\begin{array}{c}\text { Zone of trunk/ } \\
\text { tributary flow }\end{array}$ & 0.012 & -4.819 & 0.013 & 0.813 \\
${\mathrm{~B}-\mathrm{B}^{\prime}}^{\text {Cross-cutting }}$ & 0.029 & -3.853 & 0.027 & 0.786 \\
tributary 2 & & -3.667 & 0.021 & 0.602 \\
$\mathrm{C}-\mathrm{C}^{\prime}$ & $\begin{array}{c}\text { Extra-tributary } \\
\text { slow flow }\end{array}$ & 0.031 & & &
\end{tabular}

flight-lines (including the one analysed in detail above), covering $>35000 \mathrm{~km}$ (Vaughan and others, 2006). From the gridded data, roughness was then extracted along the centre line of each tributary. Figure 5 shows plots of surface velocity, bed elevation and bed roughness along each tributary, extracted from the map of interpolated roughness shown in Figure $4 \mathrm{~b}$.

A zone of low roughness is located in the central trunk of PIG and in much of the length of Tributary 5 and part of Tributary 6 which feed the main trunk (Figs $4 \mathrm{~b}$ and $5 f$ and g). Elsewhere within PIG (and the other tributaries), roughness

Table 2. Roughness in the two subsections of section B-B' (cf. Fig. 3 and caption to Table 1)

\begin{tabular}{lccccc} 
Section & Characteristics & $\begin{array}{c}\text { Mean } \\
\text { roughness }\end{array}$ & $\begin{array}{c}\text { Mean log } \\
\text { roughness }\end{array}$ & $\begin{array}{c}\text { SD } \\
\text { roughness }\end{array}$ & $\begin{array}{c}\text { SD log } \\
\text { roughness }\end{array}$ \\
\hline $\mathrm{B}-\mathrm{B}^{\prime}$ & Inside tributary & 0.015 & -4.332 & 0.007 & 0.518 \\
$\mathrm{~B}-\mathrm{B}^{\prime}$ & Outside tributary & 0.045 & -3.333 & 0.031 & 0.691
\end{tabular}



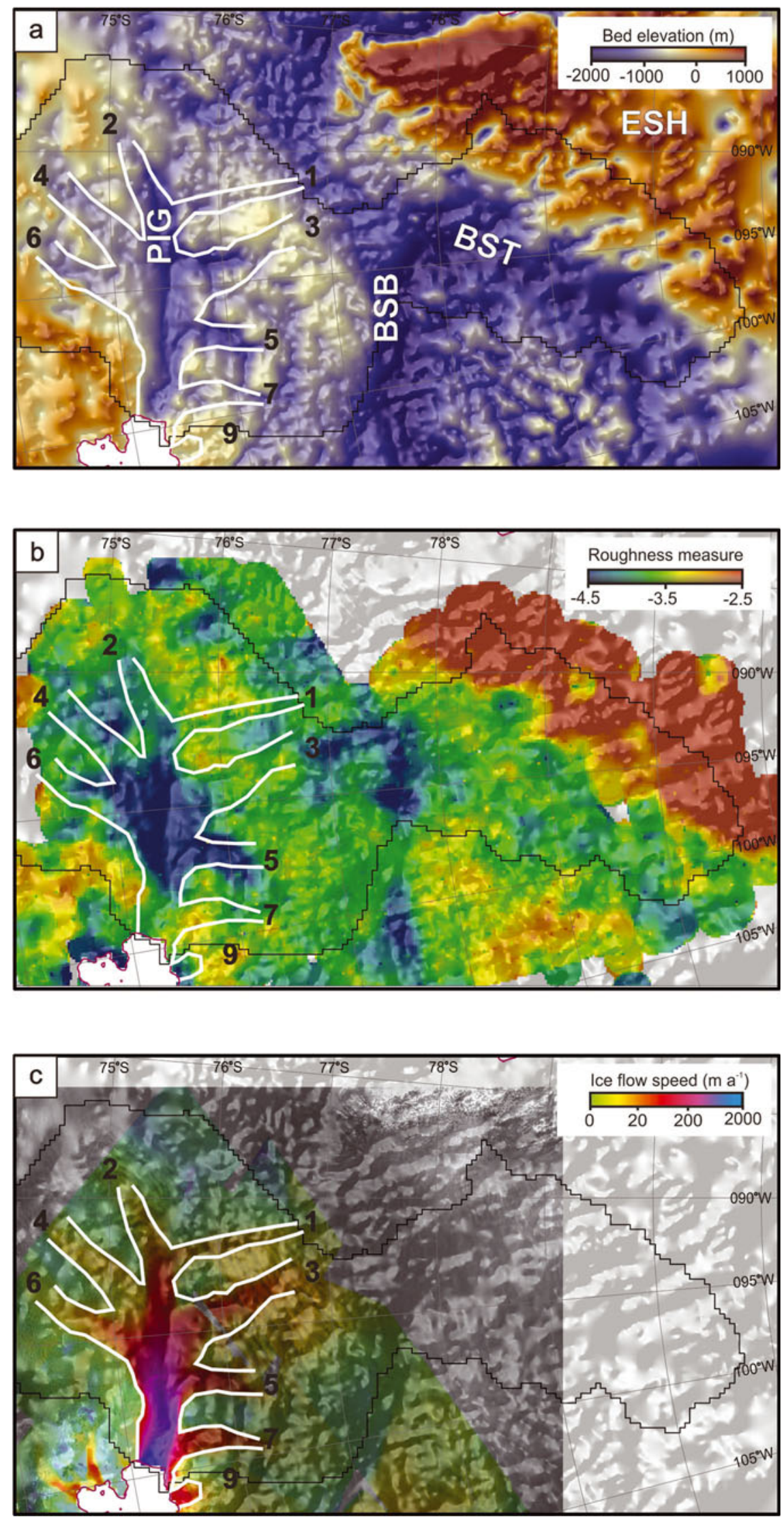

Fig. 4. (a) Bed topography across the whole PIG region (after Vaughan and others, 2006). This topography was constructed from a compilation of data from many sources, gridded with a simple inverse-distance weighting algorithm. PIG is Pine Island Glacier, BSB is the Byrd Subglacial Basin, BST is the Bentley Subglacial Trench and ESH is the Ellsworth Subglacial Highlands. The tributaries of PIG are numbered in order to aid comparison with Figure $4 \mathrm{~b}$ and c. Numbering is according to the scheme originally presented by Stenoien and Bentley (2000; cf. Vaughan and others, 2006). (b) Log of bed roughness across the PIG region. More negative numbers indicate a smoother bed, while less negative numbers indicate a rougher bed. Again, the tributaries of PIG are numbered to aid comparison with Figure $4 \mathrm{a}$ and c. (c) InSAR velocities (where available) across the region (after Rignot and others, 2004). Again, tributary numbering aids comparison with Figure $4 \mathrm{a}$ and $\mathrm{b}$. 

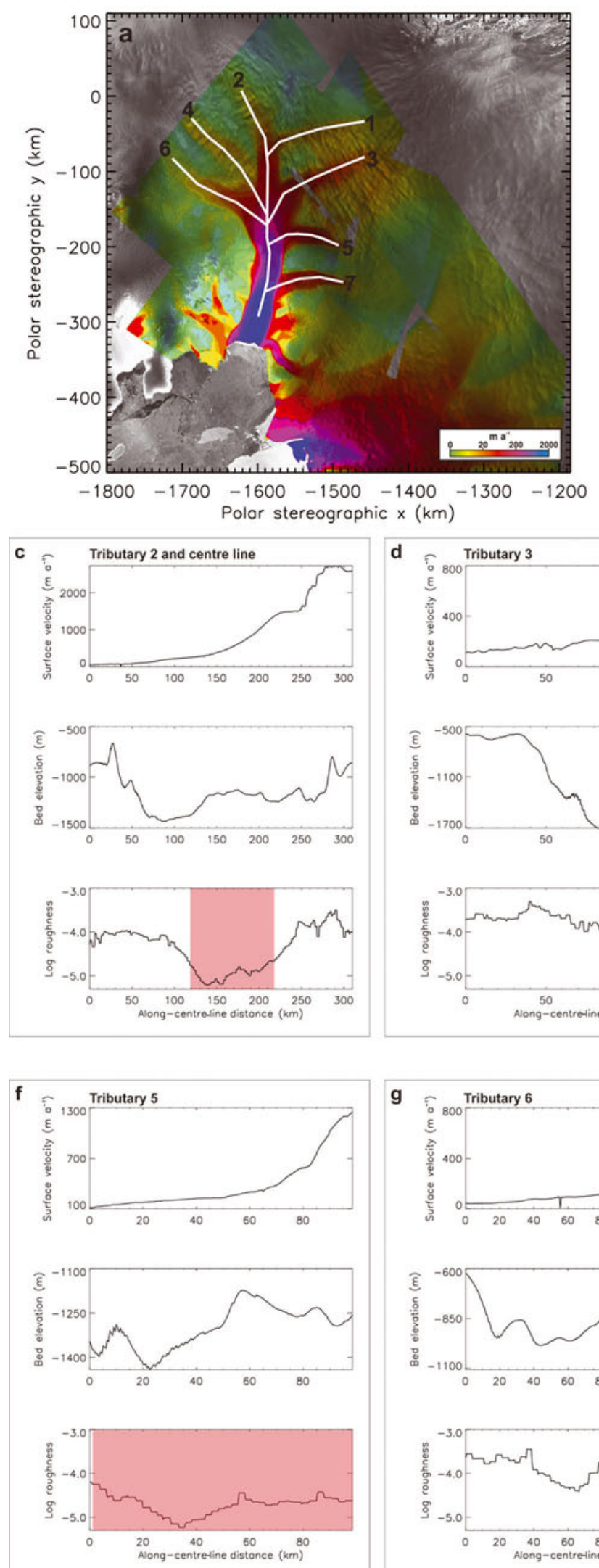
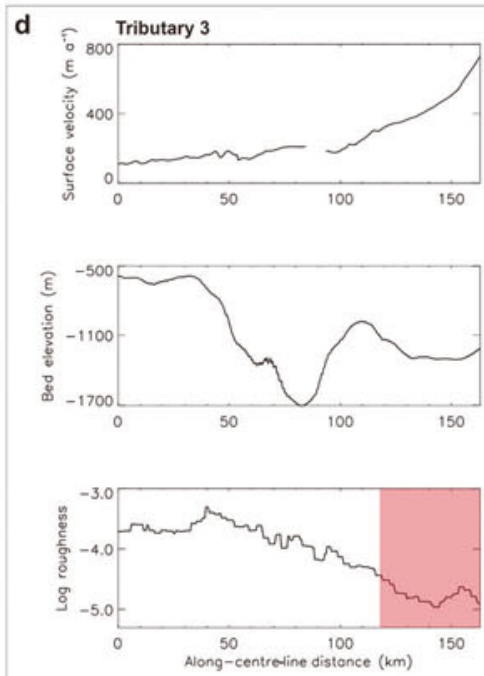

g
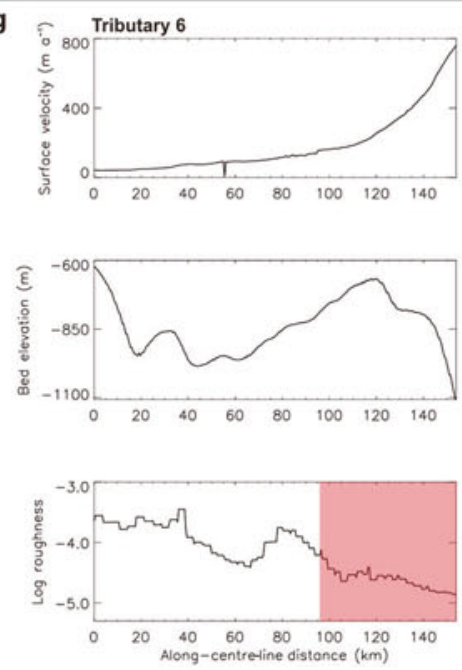
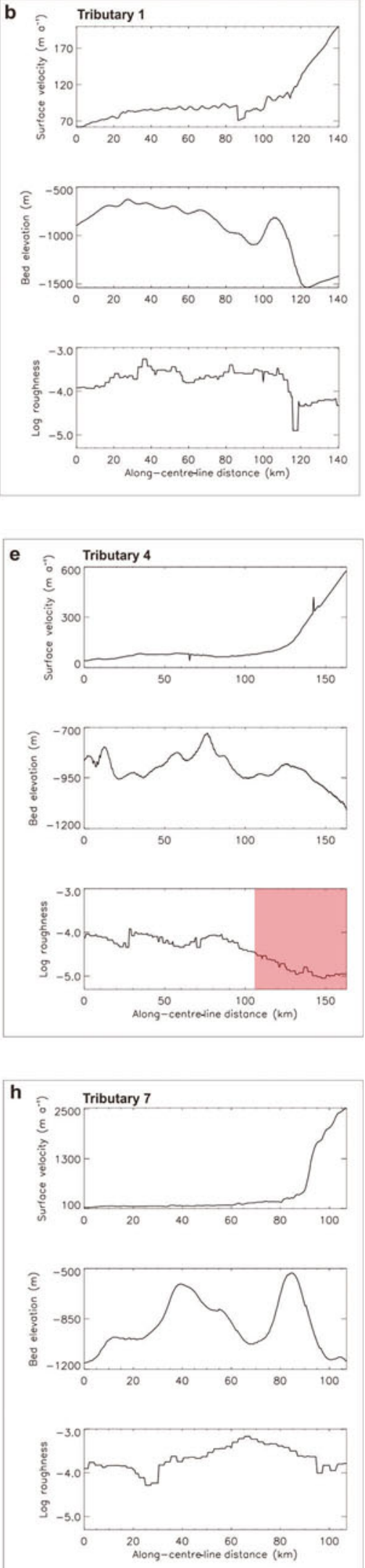

Fig. 5. Plots of surface velocity, bed elevation and bed roughness along the main PIG trunk and all the major tributaries. (a) The location of each along-tributary section (background colouring represents InSAR velocities (after Rignot and others, 2004)); tributaries are again numbered according to the scheme of Stenoien and Bentley (2000). (b-h) The three boxed line-charts show (from top to bottom): surface velocity, bed elevation and the log of roughness for: (b) Tributary 1; (c) Tributary 2 and the main glacier trunk (starting at the upper limit of Tributary 2 and ending near the grounding line of the main trunk); (d) Tributary 3; (e) Tributary 4; (f) Tributary 5; (g) Tributary 6; and (h) Tributary 7. Data were extracted from the gridded data shown in Figure 4. The $x$-axes in all line-charts represent along-tributary distance, with the right-hand side (maximum value) representing the point where the tributary joins the centre of the main PIG trunk. Note that the $y$-axis scaling on all roughness plots is identical, to aid comparison, unlike the $y$-axis for the other quantities. Regions shaded transparent red represent areas of low roughness referred to in the text. 

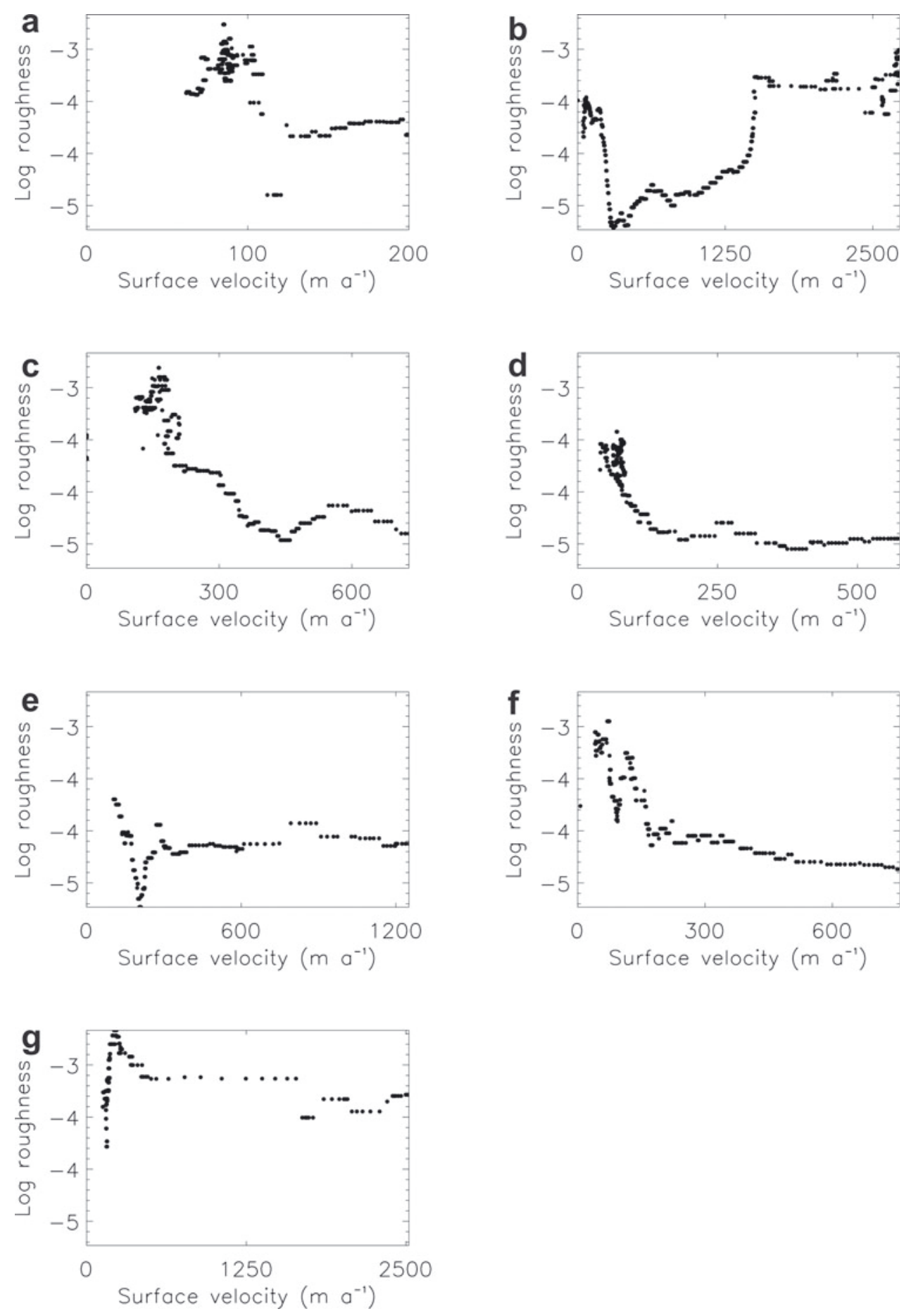

Fig. 6. Variation in basal roughness with velocity along the tributaries shown in Figure 5 a. (a) Tributary 1 ; (b) Tributary 2 and the main glacier trunk; (c) Tributary 3; (d) Tributary 4; (e) Tributary 5; (f) Tributary 6; and (g) Tributary 7.

is markedly higher, even though velocities are comparable to those on Tributaries 5 and 6 . In Figure $5 \mathrm{~d}$ and e, the lower parts of Tributaries 3 and 4 also appear smooth (shaded red), but this is where the tributaries meet the main trunk of PIG. In the tributaries themselves, roughness is higher. Outside PIG, there are also two distinct regions within the deep Byrd Subglacial Basin (BSB; Fig. 4a and b) that exhibit low roughness, but the adjacent Bentley Subglacial Trench is characterized by high roughness. Finally, the Ellsworth Subglacial Highlands are associated with particularly high roughness values (Fig. $4 \mathrm{a}$ and b).

Figure 6 shows the relationship between surface velocity and basal roughness in each of the tributaries, as defined in
Figure 5a. In Tributaries 3, 4 and 6 (Fig. 6c, d and f) particularly, velocity and roughness are related, with roughness decreasing exponentially as velocity increases, i.e. log of roughness becomes more negative. This relationship indicates a strong association between a smooth bed and fast flow. The relationship is less clear in the other tributaries and the main trunk, reflecting the fact that in some locations higher velocities are associated with a rough bed.

\section{DISCUSSION}

To gain insight into the influence of bed roughness on ice flow, we consider the range of processes that might cause a 
rough or smooth bed. Bingham and Siegert (2009, their fig. 3) detail some ideas. Of primary importance is the possibility of marine inundation following collapse or disappearance of the WAIS in the Pliocene or Pleistocene (e.g. Scherer and others, 1998; Pollard and DeConto, 2009). This would cause a smooth bed of marine sediments. Conversely, a rougher bed suggests no marine sedimentation. Pollard and DeConto (2009) do indeed show that the Pine Island area was deglaciated $\sim 200 \mathrm{ka} B P$, and Vaughan and others (2006, their fig. 1f) show that virtually the entire PIG basin was palaeoseabed in the past. Both observations strongly support the presence of marine sediments across large parts of the PIG bed.

A set of linked factors responsible for variations in bed roughness are ice dynamics, thermal regime and subglacial erosion/deposition. A smooth bed is thus related to high rates of basal erosion, as a result of faster flow, facilitated by a warmer thermal regime. Conversely, a rough bed would be a consequence of minimal erosion due to cold, slowermoving ice (Bingham and Siegert, 2009). Below, we consider our results in light of these interpretations.

\section{Importance of basal motion}

It is common to interpret basal roughness as being closely associated with rates of basal motion. We have shown that the central portion of the PIG trunk and Tributaries 5 and 6 are where the bed is smoothest and fast-flowing. In substantial parts of PIG we have also shown a clear relationship between basal roughness and velocity. Therefore it is tempting to propose a causal, positive-feedback relationship between the smooth bed and fast ice flow, i.e. that fast flow occurs because of the smooth bed, which in turn facilitates further smoothing and so on. However, we believe this represents a substantial oversimplification.

Where an ice sheet is close to equilibrium, the flux of ice is, at each point, determined only by the balance flux. The resistance to ice flow, primarily arising from basal drag and internal resistance to deformation, determines the local driving stress that produces the ice-flow speed required to match the balance flux. We can thus argue that a lowroughness (low-resistance) bed does not directly produce high rates of ice flow, but rather reduces the driving stress required to match the balance flux. This can be demonstrated from our analysis by noting that ice flow is slow over the Byrd Subglacial Basin, even though the bed in this area has very low roughness (Fig. 4).

However, it would be simplistic to assume that the correspondence between fast ice flow and low roughness was entirely coincidental. Because driving stress is related to ice thickness and surface slope, a region where basal resistance to flow is low will tend to have a lower ice surface than surrounding areas, and this would tend to channel ice flow towards areas of low basal resistance. This could contribute to the tributary structure visible in the lower reaches of the PIG basin.

Due to recent glacier acceleration, there is currently a significant fractional ( $50 \%)$ imbalance between accumulation and glacier discharge. If increases in the rate of glacier flow continue at the rates measured in recent years (e.g. Scott and others, 2009), then the relationship between basal resistance and ice-flow rate will determine the inland progression of imbalance. Where basal resistance increases rapidly with ice flow, it is likely that greater driving stresses (surface slopes) will need to be generated before acceleration can be transmitted inland. Where ice-flow speed and basal resistance are only weakly linked, as we might expect for smooth sedimentary beds, the inland transmission of imbalance and ice thinning could be more rapid. Thus, our analysis suggests that the effects of acceleration on the main trunk of the glacier will be transmitted rather differently along the various tributaries of PIG.

The coexistence of tributaries where there is a smooth bed and others with a rough bed (despite feeding the same glacier) has also been identified on Slessor Glacier, East Antarctica (Rippin and others, 2006a,b). This suggests that the spatial distribution of soft marine sediments beneath PIG (and indeed Slessor Glacier) is highly spatially variable: patchy rather than representing a large-scale and widespread emplacement of marine sediments. This implies that the whole of PIG would not respond similarly to an increase in ice flux: an increase in velocity that cannot be accommodated by internal deformation would most likely manifest itself as basal motion in those areas of PIG where the bed is smooth, but not so where the bed is rough.

Vaughan and others (2006) showed that the trunk and main tributaries of PIG lie in deep and confined topographic lows. They suggested that this indicates PIG is a relatively stable feature, with no evidence of tributary migration. Our analysis indicates that areas of smooth bed are located within these topographic lows, so we suggest that fast flow due to basal motion (that might come about due to changes in ice flux) is likely to be constrained within these troughs.

\section{Roughness and basal drag}

Our findings are also of interest when viewed in the light of the work of Vieli and Payne (2003), who used a control method to determine basal friction beneath PIG from surface velocities. They identified a region a short way upstream of the grounding line where basal drag is high, while further up-glacier, longitudinal and lateral resistive stresses are more important, and basal drag is consequently lower. Similarly, Thomas and others (2004) also identified a region of high basal drag just upstream of the grounding line with significantly reduced drag further up-glacier. Furthermore, Joughin and others' (2009) modelling studies indicate that extensive areas of weak bed exist along much of PIG's trunk. However, they also conclude that PIG has 'mixed bed conditions' in which there are alternating areas of low and high basal drag, interpreted as deforming sediments, and non-deforming sediments or bedrock respectively (Joughin and others, 2009).

These other results are well supported by our findings of: (1) a bed with variable basal roughness; and (2) a main trunk in which the lower part is an area of high basal roughness (and thus high friction/drag) while further up-glacier, reduced roughness (and low basal drag) dominates. Nevertheless, as stated previously, despite variable basal drag, we demonstrate that substantial basal sliding is currently not occurring in PIG. This is supported by Scott and others (2009) who show that recently observed acceleration in PIG can be explained by increases in gravitational driving stress.

\section{Outside PIG}

Outside PIG, the deep subglacial trough of the BSB is also similarly associated with substantial regions (albeit less extensive) of smooth bed (Fig. 4). Although InSAR coverage for this region is limited, balance velocity calculations suggest that surface velocities are slightly elevated above the 
slow flow of surrounding areas, but substantially lower than velocities within PIG. Our analysis of bed roughness, however, indicates that roughness in parts of BSB is nearly as low as in PIG. Again, this observation indicates the presence of a significant area of marine sediments that would facilitate basal motion in the event of substantial changes in ice flux.

\section{CONCLUSIONS}

We have used a new RES dataset from the Amundsen Sea sector of West Antarctica to investigate basal roughness in the vicinity of PIG. In line with other workers, we interpret a smooth bed to indicate significant deposits of marine sediments, laid down following collapse or disappearance of the WAIS $\sim 200 \mathrm{ka}$ BP.

Although our analysis suggests a link between ice velocity and bed roughness, such that velocities are higher where the bed is smoother, and lower where the bed is rougher, we suggest only an indirect relationship between the two. In other words, a smooth bed does not directly produce high rates of ice flow, but rather the need for a lower driving stress to achieve the balance flux. As a consequence, the surface is lower and so ice is drawn down from surrounding rougher areas into this smooth area. The fact that roughness varies widely across the PIG tributaries suggests that velocity changes on the main trunk will be differentially transmitted back into the interior along them.

We also verify the modelled basal drag fluctuations, determined by other workers, indicating that elevated basal drag in PIG may be a result of increased basal roughness (Vieli and Payne, 2003; Thomas and others, 2004). Our work also supports modelling studies that identify patchy bed conditions in which roughness and thus resistance to flow varies over short distances (cf. Joughin and others, 2009).

Ice-stream reorganization and migration has been reported from the Siple Coast region of West Antarctica (e.g. Conway and others, 2002; Christoffersen and Tulaczyk, 2003; Catania and others, 2005). This is possible because of the minimal topographic restrictions on the Siple Coast ice streams, meaning they are able to laterally migrate relatively easily (Catania and others, 2003). In the case of PIG, however, Vaughan and others (2006) suggested that it is unlikely that a collapse initiated along the trunk would extend into the deepest parts of the WAIS, because the trunk and tributaries of PIG lie in deep, confining subglacial troughs and are enclosed by a ridge in the bed topography. Our roughness assessment supports this, since a lack of smooth bed beyond the current limits of PIG and its tributaries indicates that any substantial increase in ice velocity due to basal sliding would not extend here, or at least that it would not be favoured in these rough-bed areas. We propose that PIG and its contributing tributaries could be considered as relatively stable West Antarctic fast-flow features (in terms of their location and extent), but that any dynamic response due to changes in ice flux would be felt with significant spatial variability in PIG, such that different tributaries, and indeed different parts of tributaries and the trunk, would speed up to different degrees. Thus, exploration of future dynamics changes in PIG should focus on the likely variability of these responses. Beyond work in PIG, indentifying areas of bed undergoing active smoothing would be of great benefit for investigations into the causal link between basal roughness and ice dynamics.

\section{ACKNOWLEDGEMENTS}

We acknowledge the logistical support for the field campaign of the British Antarctic Survey and the US National Science Foundation. This work was also conducted in collaboration with the University of Texas. We thank the field party, and L. Byrne, who digitized the radar data. We also thank two anonymous referees for their detailed and considered comments, which helped to improve the paper.

\section{REFERENCES}

Bennett, M.R. 2003. Ice streams as the arteries of an ice sheet: their mechanics, stability and significance. Earth-Sci. Rev., 61(3-4), 309-339.

Bindschadler, R. 1983. The importance of pressurized subglacial water in separation and sliding at the glacier bed. J. Glaciol., 29(101), 3-19.

Bingham, R.G. and M.J. Siegert. 2007. Radar-derived bed roughness characterization of Institute and Möller ice streams, West Antarctica, and comparison with Siple Coast ice streams. Geophys. Res. Lett., 34(21), L21504. (10.1029/2007GL031483.)

Bingham, R.G. and M.J. Siegert. 2009. Quantifying subglacial bed roughness in Antarctica: implications for ice-sheet dynamics and history. Quat. Sci. Rev., 28(3-4), 223-236.

Bingham, R.G., M.J. Siegert, D.A. Young and D.D. Blankenship. 2007. Organized flow from the South Pole to the FilchnerRonne ice shelf: an assessment of balance velocities in interior East Antarctica using radio echo sounding data. J. Geophys. Res., 112(F3), F03S26. (10.1029/2006JF000556.)

Brigham, E.O. 1988. Fast Fourier transform and its applications. Upper Saddle River, NJ, Prentice Hall.

Catania, G.A., H.B. Conway, A.M. Gades, C.F. Raymond and H. Engelhardt. 2003. Bed reflectivity beneath inactive ice streams in West Antarctica. Ann. Glaciol., 36, 287-291.

Catania, G.A., H. Conway, C.F. Raymond and T.A. Scambos. 2005. Surface morphology and internal layer stratigraphy in the downstream end of Kamb Ice Stream, West Antarctica. J. Glaciol., 51(174), 423-431.

Christoffersen, P. and S. Tulaczyk. 2003. Thermodynamics of basal freeze-on: predicting basal and subglacial signatures of stopped ice streams and interstream ridges. Ann. Glaciol., 36, 233-243.

Conway, H., G. Catania, C. Raymond, T. Scambos, H. Engelhardt and A. Gades. 2002. Switch of flow direction in an Antarctic ice stream. Nature, 419(6906), 465-467.

Harper, J.T., N.F. Humphrey, W.T. Pfeffer and B. Lazar. 2007. Two modes of accelerated glacier sliding related to water. Geophys. Res. Lett., 34(12), L12503. (10.1029/2007GL030233.)

Hubbard, B., M.J. Siegert and D. McCarroll. 2000. Spectral roughness of glaciated bedrock geomorphic surfaces: implications for glacier sliding. J. Geophys. Res., 105(B9), 21,295-21,303.

Iken, A. 1981. The effect of the subglacial water pressure on the sliding velocity of a glacier in an idealized numerical model. J. Glaciol., 27(97), 407-421.

Jansson, P. 1995. Water pressure and basal sliding on Storglaciären, northern Sweden. J. Glaciol., 41(138), 232-240.

Joughin, I. and 6 others. 2009. Basal conditions for Pine Island and Thwaites Glaciers, West Antarctica, determined using satellite and airborne data. J. Glaciol., 55(190), 245-257.

Lliboutry, L. 1987. Realistic, yet simple bottom boundary conditions for glaciers and ice sheets. J. Geophys. Res., 92(B9), 9101-9109.

Pollard, D. and R.M. DeConto. 2009. Modelling West Antarctic ice sheet growth and collapse through the past five million years. Nature, 458(7236), 329-332.

Rignot, E.J. 1998. Fast recession of a West Antarctic glacier. Science, 281(5376), 549-551.

Rignot, E. and 11 others. 2004. Improved estimation of the mass balance of the glaciers draining into the Amundsen Sea sector of 
West Antarctica from the CECS/NASA 2002 campaign. Ann. Glaciol., 39, 231-237.

Rippin, D.M., J.L. Bamber, M.J. Siegert, D.G. Vaughan and H.F.J. Corr. 2006a. Basal conditions beneath enhanced-flow tributaries of Slessor Glacier, East Antarctica. J. Glaciol., 52(179), 481-490.

Rippin, D.M., M.J. Siegert, J.L. Bamber, D.G. Vaughan and H.F.J. Corr. 2006b. Switch-off of a major enhanced ice flow unit in East Antarctica. Geophys. Res. Lett., 33(15), L15501. (10.1029/2006GL026648.)

Scherer, R.P., A. Aldahan, S. Tulaczyk, G. Possnert, H. Engelhardt and B. Kamb. 1998. Pleistocene collapse of the West Antarctic ice sheet. Science, 281(5373), 82-85.

Scott, J.B.T., G.H. Gudmundsson, A.M. Smith, R.G. Bingham, H.D. Pritchard and D.G. Vaughan. 2009. Increased rate of acceleration on Pine Island Glacier is strongly coupled to thinning induced changes in driving stress. Cryosphere, 3(1), 125-131.

Shepherd, A., D. Wingham and E. Rignot. 2004. Warm ocean is eroding West Antarctic Ice Sheet. Geophys. Res. Lett., 31(23), L23404. (10.1029/2004GL021106.)

Siegert, M.J., J. Taylor, A.J. Payne and B. Hubbard. 2004. Macroscale bed roughness of the Siple Coast ice streams in West Antarctica. Earth Surf. Process. Landf., 29(13), 1591-1596.

Siegert, M.J., J. Taylor and A.J. Payne. 2005. Spectral roughness of subglacial topography and implications for former ice-sheet dynamics in East Antarctica. Global Planet. Change, 45(1-3), 249-263.

Stenoien, M.D. and C.R. Bentley. 2000. Pine Island Glacier, Antarctica: a study of the catchment using interferometric synthetic aperture radar measurements and radar altimetry. J. Geophys. Res., 105(B9), 21,761-21,779.

Taylor, J., M.J. Siegert, A.J. Payne and B. Hubbard. 2004. Regionalscale roughness beneath ice masses: measurement and analysis. Comput. Geosci., 30(8), 797-908.

Thomas, R.H., E.J. Rignot, K. Kanagaratnam, W.B. Krabill and G. Casassa. 2004. Force-perturbation analysis of Pine Island Glacier, Antarctica, suggests cause for recent acceleration. Ann. Glaciol., 39, 133-138.

Truffer, M. and K.A. Echelmeyer. 2003. Of isbræ and ice streams. Ann. Glaciol., 36, 66-72.

Vaughan, D.G. and 9 others. 2001. A review of Pine Island Glacier basin, West Antarctica: hypotheses of instability vs. observations of change. In Bindschadler, R.A. and R.B. Alley, eds. The West Antarctic ice sheet: behavior and environment. Washington, DC, American Geophysical Union, 237-256. (Antarctic Research Series 77. .

Vaughan, D.G. and 9 others. 2006. New boundary conditions for the West Antarctic ice sheet: subglacial topography beneath Pine Island Glacier. Geophys. Res. Lett., 33(9), L09501. (10.1029/2005GL025588.)

Vaughan, D.G., A. Rivera, J. Woodward, H. Corr, J. Wendt and R. Zamora. 2007. Topographic and hydrological controls on Subglacial Lake Ellsworth, West Antarctica. Geophys. Res. Lett., 34(18), L18501. (10.1029/2007GL030769.)

Vieli, A. and A.J. Payne. 2003. Application of control methods for modelling the flow of Pine Island Glacier, Antarctica. Ann. Glaciol., 36, 197-204.

Willis, I.C. 1995. Intra-annual variations in glacier motion: a review. Progr. Phys. Geogr., 19(1), 61-106. 